\title{
Bioethanol Production from Switchgrass Grown on Coal Fly Ash-amended Soil
}

\author{
Olushola M. Awoyemi*, Ekundayo O. Adeleke \\ Department of Agricultural and Environmental Sciences, Tennessee State University, Nashville, TN 37209, USA \\ *Corresponding author: doctoroma@yahoo.com
}

Received March 29, 2017; Revised April 29, 2017; Accepted May 22, 2017

\begin{abstract}
Potentially toxic concentrations of certain mineral elements may be taken up in plant biomass produced on coal fly ash (CFA) contaminated soil. This raises concerns about efficiencies of downstream processes, such as hydrolysis and fermentation involved in biomass conversions to bioethanol. A greenhouse pot experiment was conducted to assess bioethanol yield from switchgrass biomass produced on CFA-amended soil (0, 7.5 and $15 \%$, w/w CFA/soil). Separate aliquots of the CFA-amended soils were either inoculated with isolate of arbuscular mycorrhizal fungi (AMF), Rhizophagus clarus, or fortified with reduced glutathione (GSH). Mineral elements in the CFA-amended soils and plant tissues were determined using ICP-OES. Shoot samples of harvested biomass were subjected to microwave-assisted acid pretreatment, enzymatic hydrolysis and fermentation. The reducing sugar (glucose) and bioethanol in the biomass hydrolysate were determined by spectrophotometry. Results showed that CFA had a concentration-dependent increase on the levels of the mineral elements in soils that were amended. Subsequent uptake of the mineral elements in switchgrass tissues was modulated by CFA-soil amendment, AMF inoculation, and GSH fortification. The glucose concentrations in biomasss hyzrolysate of switchgrass grown on 7.5 and 15\% CFA-amended soils were significantly higher $(\mathrm{p}<0.05)$ than the unamended (control) soil without significant adverse effect on the bioethanol yield. The bioethanol concentration $(\mu \mathrm{g} / \mathrm{mg} \mathrm{DW})$ in the fermented hydrolysate of switchgrass grown on 15\% CFA-amended soil (26.63) was higher than the control soil (24.46). Likewise, AMF and GSH enhanced bioethanol yield from hydrolysate of switchgrass biomass grown on the CFA-amended soil. Our results indicated that coupling CFA-amended soil with either AMF or GSH can enhance bioethanol yield.
\end{abstract}

Keywords: coal fly ash, bioethanol, switchgrass biomass, enzymatic hydrolysis, fermentation, mineral element translocation

Cite This Article: Olushola M. Awoyemi, and Ekundayo O. Adeleke, "Bioethanol Production from Switchgrass Grown on Coal Fly Ash-amended Soil.” World Journal of Agricultural Research, vol. 5, no. 3 (2017): 147-155. doi: 10.12691/wjar-5-3-4.

\section{Introduction}

Coal Fly ash (CFA), a byproduct of coal combustion processes consists essentially of $\mathrm{SiO}_{2}, \mathrm{Al}_{2} \mathrm{O}_{3}$, and various micro and macro mineral elements [1,2]. CFA mineral element compositions along with other properties make it suitable as soil amendment to supplement deficient elements in marginal soils for cultivating bioenergy crops [3]. However, the concentration of these mineral elements may exceed their normal levels in agricultural. Depending on the levels of these mineral elements in soils amended or contaminated with CFA, lignocellulosic biomass and downstream bioethanol production may be affected $[4,5,6]$. Biomass can be converted to bioethanol by enzymatic hydrolysis and sugar fermentation processes $[7,8]$.

The importance of biofuel as a sustainable approach in mitigating the increasing price and negative environmental and human impacts of fossil fuels is increasingly recognized $[9,10,11]$. Unlike fossil fuels, biofuel is a renewable energy source and more eco-friendly [12]. The principal biofuel commercially used in many countries as a petrol substitute or in addition to petrol/gasoline is bioethanol $[13,14]$. Despite US been the current world's largest producer of ethanol, with an output more than double that of the next-largest producer, Brazil, there is still an increasing demand for more bioethanol $[15,16]$.

Lignocellulosic feedstocks such as switchgrass (Panicum virgatum L.), have been proposed to offer energy and environmental, and economic advantages over current biofuel sources (corn and sugarcane). This is because switchgrass is a perennial crop which requires fewer agricultural inputs than compared to annual crops and can be grown on marginal lands [17]. Studies have shown switchgrass to be a viable bioenergy crop because it produces high yields on marginal lands under low water and nutrient conditions $[17,18,19,20,21]$.

It has been noted that the presence of mineral elements including heavy metals might or might not affect yield of ethanol from biomass $[6,18,22,23,24,25,26]$. It remains unclear whether the elevated levels of mineral elements in CFA could affect fermentation processes and direct tests for fermentation of switchgrass grown on 
CFA-contaminated/amended soils are lacking. In this study, we present experimental results to address this issue.

The main objective of the present work was to assess at laboratory scale the bioethanol production path of switchgrass biomass grown on CFA-amended soils with emphasis on distribution of mineral elements. This study examined the effects of coal fly ash (CFA) used as soil amendment on the multitasking capability of lignocellulosic species switchgrass (Panicum virgatum). These include mineral elements uptake (including bioaccumulation, enrichment, and translocation), glucose and bioethanol yield from enzymatic hydrolysis (saccharification) and hydrolysate fermentation respectively. The effects of arbuscular mycorrhizal fungi (AMF, Rhizophagus clarus) and exogenous glutathione (GSH) in modulating the switchgrass capabilities were also investigated.

\section{Materials and Methods}

\subsection{Materials}

All chemicals were reagent grade. Sodium acetate trihydrate, and acetic acid (glacial) were obtained from Fisher Scientific (Pittsburgh, PA). Cycloheximide, tetracycline (Fluka), d-glucose standard, microcrystalline cellulose, glucose (HK) assay kit and ethanol assay kit were obtained from Sigma-Aldrich (St. Louis, MO). Accellerase 1500 enzyme was provided by Genencor (Rochester, NY). Ethanol TT yeast was provided by SPL International (Cheshire, United Kingdom). Yeast extract was obtained from Acros Organics (Geel, Belgium) and molecular biology grade peptone was obtained from U.S. Biological (Swampscott, MA). AMF (R. clarus, WV234) was obtained from INVAM, the International Culture Collection of Vesicular Arbuscular Mycorrhizal Fungi, Morgantown, WV and GSH was purchased from obtained from Acros Organic, New Jersey, USA. All solutions were prepared using sterilized deionized (DI) water.

\subsection{Soil Preparation, Switchgrass Culture and Determination of Harvested Biomass}

Armor silt loam (ASL) soil collected from obtained from Tennessee State University Agricultural Research, Education Center, Nashville TN was sieved through $2 \mathrm{~mm}$ sieve, and appropriate amounts of CFA were added to separate portions of the soil to provide CFA-soil admixtures (0, 7.5 and 15\% w/w CFA/soil). Exactly 1.5 $\mathrm{kg}$ of each portion of CFA-soil admixture was introduced into plastic pots (5-inch deep). Seeds of 'Alamo' variety of switchgrass (P. virgatum L.) obtained from Star Seeds Inc., Osborne, Kansas, were started in germination trays containing potting mix (Farfard \#2 mix) and 2-leaf stage seedlings (4 weeks old) of the switchgrass were transplanted in the pots containing different treatments of CFA-soil admixtures. Treatments in four replicates consisted of: a) CFA-soil admixtures only; b) CFA-soil admixtures fortified with $0.4 \mathrm{mg} / \mathrm{kg} \mathrm{GSH}$; and c) CFA-soil admixtures inoculated with 3\% turface containing AMF, $R$. clarus. Transplanted switchgrass seedlings were allowed to grow for a period of 90 days and then harvested.
Harvested plants were oven dried at $70{ }^{\circ} \mathrm{C}$ to constant weight.

\subsection{Determination of the Concentrations of Selected Mineral Elements in Samples (CFA-soil Admixtures and Plant Tissues)}

Air-dried soil samples $(0.25 \mathrm{~g})$ at days 0 and 90 were digested with $10 \mathrm{ml}$ of concentrated $\mathrm{HNO}_{3}$ [27]. Oven dried and milled samples $(0.25 \mathrm{~g})$ of switchgrass root and shoot biomass were digested with concentrated $\mathrm{H}_{2} \mathrm{O}_{2} / \mathrm{HNO}_{3}$ (1:3) [28]. Digestion was carried out in a microwave assisted accelerated reaction system (MARS5 v194A08; CEM corporation) at $170^{\circ} \mathrm{C}$ for $10 \mathrm{~min}$. The concentrations of mineral elements ( $\mathrm{K}, \mathrm{P}, \mathrm{Mg}, \mathrm{Ca}, \mathrm{Na}, \mathrm{S}$, $\mathrm{Si}, \mathrm{B}, \mathrm{Al}, \mathrm{Fe}, \mathrm{Mn}$, and $\mathrm{Co}$ ) in the digests were determined using ICP-OE Spectrometer (iCAP 7000 series, Thermo Scientific).

\subsection{Microwave-assisted Acid Pretreatment (MAAP) of Biomass}

Dried and milled samples of switchgrass shoot biomass $(0.25 \mathrm{~g})$ were pretreated with $10 \mathrm{~mL}$ dilute $\mathrm{HNO}_{3}$ acid (5.0\%) using a microwave heating unit (MARS5 v194A08; CEM corporation) at $170{ }^{\circ} \mathrm{C}$ for $10 \mathrm{~min}$. The hydrolysate of the pretreated switchgrass biomass was made up to 50 $\mathrm{mL}$ with $\mathrm{DI} \mathrm{H}_{2} \mathrm{O}$ and $\mathrm{pH}$ was adjusted to 5.5 using $\mathrm{KOH}$ (1.0 $\mathrm{M}$ and $1.0 \mathrm{mM}$ ). The hydrolysate was stored in 50 $\mathrm{mL}$ tubes at $4^{\circ} \mathrm{C}$ for enzymatic hydrolysis.

\subsection{Enzymatic Hydrolysis Reactions}

Enzymatic hydrolysis reactions were carried out with 1.0 M sodium acetate buffer ( $\mathrm{pH} 4.8)$, with addition of antibiotics to prevent microbial growth [29,30]. For the cellulose reaction, approximately $0.5 \mathrm{~g}$ cellulose was placed in a $25 \mathrm{~mL}$ Erlenmeyer flask followed by the addition of $23.5 \mathrm{~mL}$ sterilized DI $\mathrm{H}_{2} \mathrm{O}, 0.25 \mathrm{~mL}$ Accellerase $1500, \quad 150 \mu \mathrm{L}$ cycloheximide, $100 \mu \mathrm{L}$ tetracycline (10 g/L in $70 \%$ ethanol) and $1.25 \mathrm{~mL}$ acetate buffer. For the biomass reaction, approximately $23.5 \mathrm{~mL}$ pretreated hydrolysate containing switchgrass biomass was placed in a 25-mL Erlenmeyer flask followed by the addition of $0.25 \mathrm{~mL}$ Accellerase 1500 enzyme, $150 \mu \mathrm{L}$ cycloheximide, $100 \mu \mathrm{L}$ tetracycline and $1.25 \mathrm{~mL}$ acetate buffer. Flasks were capped and placed in an incubated shaker at $50{ }^{\circ} \mathrm{C}, 250 \mathrm{rpm}$ for $48 \mathrm{~h}$. The mixtures were heated to $60{ }^{\circ} \mathrm{C}$ to terminate the enzymatic reaction at the end of the incubation period. Samples were then centrifuged at approximately $6200 \times \mathrm{g}$ for $20 \mathrm{~min}$ and the supernatants were filtered using a $0.22 \mu \mathrm{m}$ filter. The concentrations of glucose in the hydrolysate were determined by spectrophotometry with absorbance read at $340 \mathrm{~nm}$.

\subsection{Fermentation Reactions}

A 10× YP medium was prepared by dissolving $10.0 \mathrm{~g}$ yeast extract and $20.0 \mathrm{~g}$ peptone in $100 \mathrm{~mL}$ deionized water followed by autoclaving at $121{ }^{\circ} \mathrm{C}$ for $30 \mathrm{~min}$. For the glucose fermentation, a mixture of $1.0 \mathrm{~mL}$ acetate 
buffer $(\mathrm{pH} 4.8), 1.0 \mathrm{~mL}$ of $10 \times \mathrm{YP}, 3.0 \mathrm{~mL}$ glucose solution, $0.02 \mathrm{~g}$ of ethanol TT yeast, and $5.0 \mathrm{~mL}$ autoclaved water was added to the $25 \mathrm{~mL}$ Erlenmeyer flask. For the fermentation of hydrolysate, a mixture of 1.0 $\mathrm{mL}$ pH 4.8 acetate buffer, $1.0 \mathrm{~mL}$ of $10 \times \mathrm{YP}, 10.0 \mathrm{~mL}$ hydrolysate, $0.02 \mathrm{~g}$ of ethanol TT yeast, and $2.0 \mathrm{~mL}$ autoclaved water was added to the $25 \mathrm{~mL}$ Erlenmeyer flask. Each flask was capped with an airlock containing $1 \% \mathrm{H}_{2} \mathrm{SO}_{4}$ to allow $\mathrm{CO}_{2}$ to escape while maintaining an anaerobic environment. The entire assembly was then placed in an incubated shaker set at $32{ }^{\circ} \mathrm{C}, 130 \mathrm{rpm}$ for $48 \mathrm{~h}$ [29]. Concentrations of ethanol in the fermented solution were determined by spectrophotometry with absorbance read at $570 \mathrm{~nm}$.

\section{Results}

\subsection{Mineral Elements Status ( $\mu \mathrm{g} / \mathrm{g})$ of the ASL Soil, CFA and CFA-soil Admixtures}

The concentrations of mineral elements in the control soil, CFA-soil admixtures and CFA at the initial preparation of the admixtures are presented in Table 1. The concentrations of $\mathrm{K}, \mathrm{Mg}, \mathrm{Ca}, \mathrm{Na}, \mathrm{S}, \mathrm{B}, \mathrm{Al}$, and $\mathrm{Fe}$ were higher in the CFA compared to the control soil while $\mathrm{P}, \mathrm{Si}, \mathrm{Mn}$, and Co were lower in the CFA than the soil. The variations in the concentrations of the mineral elements between the CFA and ASL soil were significant at ( $<$ 0.05) for Mg, Ca, Na, S, Si, B, Al, Mn, and Co. The concentrations of $\mathrm{P}, \mathrm{Mg}, \mathrm{Ca}, \mathrm{Na}, \mathrm{S}, \mathrm{B}$, and $\mathrm{Co}$ increased in the CFA-soil admixtures while $\mathrm{K}, \mathrm{Al}, \mathrm{Fe}$, and Mn decreased with increased concentrations of CFA in the admixtures compared to the control.

\subsection{Mineral Elements Status $(\mu \mathrm{g} / \mathrm{g})$ of the CFA-soil Admixtures after 90 Days Pot Study}

The concentrations of mineral elements in the CFA-soil admixtures at the end of the greenhouse pot study are presented in Table 2. The concentrations of the mineral elements in the CFA-soil admixtures ranged from $9.48 \mu \mathrm{g} / \mathrm{g}$ for Co to $18869.11 \mu \mathrm{g} / \mathrm{g}$ for $\mathrm{Fe}$. The concentrations of $\mathrm{K}, \mathrm{P}, \mathrm{Mg}, \mathrm{Ca}, \mathrm{Na}, \mathrm{S}, \mathrm{B}, \mathrm{Al}, \mathrm{Fe}$, and Co were higher in the 7.5 and 15\% CFA-soil admixtures compared to the control while $\mathrm{Si}$ and $\mathrm{Mn}$ were lower (Table 2). The concentrations of $\mathrm{K}, \mathrm{P}, \mathrm{Mg}, \mathrm{Si}$, and $\mathrm{Al}$ were higher in control soil inoculated with AMF compared to uninoculated. Likewise, $\mathrm{K}, \mathrm{P}$, and $\mathrm{Mg}$ in $7.5 \%$ CFA-soil admixture, and $\mathrm{P}$ and $\mathrm{Ca}$ in 15\% CFA-soil admixture were higher with AMF inoculation compared to uninoculated admixtures (Table 2). The concentrations of $\mathrm{P}, \mathrm{S}$, and $\mathrm{Si}$ were higher in control soil fortified with GSH compared to unfortified soil. Likewise, $\mathrm{P}, \mathrm{Mg}, \mathrm{Ca}, \mathrm{Na}, \mathrm{S}, \mathrm{Si}$, and $\mathrm{B}$ in 7.5\% CFA-soil admixture and $\mathrm{P}, \mathrm{Mg}$, $\mathrm{Ca}$, and $\mathrm{S}$ in $15 \%$ CFA-soil admixture were higher with GSH fortification compared to unfortified admixtures (Table 2).

Table 1. Concentrations (mean \pm SD) of mineral elements in the CFA-soil admixtures at the start of greenhouse pot study

\begin{tabular}{|c|c|c|c|c|}
\hline Mineral Elements ( $\mu \mathrm{g} / \mathrm{g})$ & Soil + 0\% CFA (control) & Soil + 7.5\% CFA & Soil $+15 \%$ CFA & $100 \%$ CFA \\
\hline $\mathrm{K}$ & $2203.24 \pm 360.38^{\mathrm{a}}$ & $2007.64 \pm 147.90^{\mathrm{a}}$ & $2066.84 \pm 160.61^{\mathrm{a}}$ & $2659.32 \pm 325.21$ \\
\hline $\mathrm{P}$ & $3089.32 \pm 216.84^{\mathrm{a}}$ & $3263.32 \pm 118.46^{\mathrm{ab}}$ & $3478.32 \pm 195.57^{b}$ & $2812.51 \pm 127.02$ \\
\hline $\mathrm{Mg}$ & $2348.80 \pm 423.01^{\mathrm{a}}$ & $2958.90 \pm 486.40^{\mathrm{a}}$ & $2966.70 \pm 281.81^{\mathrm{a}}$ & $5460.15 \pm 760.50 *$ \\
\hline $\mathrm{Ca}$ & $2699.90 \pm 38.96^{\mathrm{a}}$ & $8729.30 \pm 1530.30^{\mathrm{b}}$ & $15220.40 \pm 1793.83^{c}$ & $49718.00 \pm 13918.94^{*}$ \\
\hline $\mathrm{Na}$ & $125.80 \pm 3.84^{\mathrm{a}}$ & $294.70 \pm 12.62^{\mathrm{b}}$ & $597.70 \pm 133.13^{\mathrm{c}}$ & $1545.15 \pm 374.77^{*}$ \\
\hline $\mathrm{S}$ & $540.50 \pm 11.12^{\mathrm{a}}$ & $2022.20 \pm 235.58^{b}$ & $3459.30 \pm 151.78^{c}$ & $8271.75 \pm 205.44^{*}$ \\
\hline $\mathrm{Si}$ & $273.94 \pm 15.29^{a}$ & $311.74 \pm 46.25^{\mathrm{ab}}$ & $331.44 \pm 14.63^{\mathrm{b}}$ & $128.32 \pm 13.05^{*}$ \\
\hline B & $23.48 \pm 1.86^{\mathrm{a}}$ & $98.48 \pm 11.09^{\mathrm{b}}$ & $189.17 \pm 5.02^{c}$ & $680.94 \pm 142.58^{*}$ \\
\hline $\mathrm{Al}$ & $20110.00 \pm 1118.75^{a}$ & $18148.70 \pm 1956.85^{\mathrm{ab}}$ & $16888.80 \pm 713.60^{c}$ & $28586.35 \pm 8176.61 *$ \\
\hline $\mathrm{Fe}$ & $32584.96 \pm 2748.64^{\mathrm{a}}$ & $30136.96 \pm 3978.27^{\mathrm{a}}$ & $28001.86 \pm 922.60^{\mathrm{a}}$ & $37921.48 \pm 11970.22$ \\
\hline Mn & $1368.16 \pm 161.50^{\mathrm{a}}$ & $1157.36 \pm 192.65^{\mathrm{ab}}$ & $1001.56 \pm 153.33^{c}$ & $151.93 \pm 16.15^{*}$ \\
\hline Co & $19.26 \pm 2.27^{\mathrm{a}}$ & $19.36 \pm 1.86^{\mathrm{a}}$ & $21.26 \pm 1.51^{\mathrm{a}}$ & $15.23 \pm 0.91^{*}$ \\
\hline
\end{tabular}

Data with different alphabets indicate significant differences between treatments ( $<<0.05$, Duncan multiple range test). CFA data with asterisks $(*)$ are significantly different compared to the control soil ( $\mathrm{p}<0.05$, one-way ANOVA).

Table 2. Average values of mineral elements in the CFA-soil admixtures after 90 days of greenhouse pot study

\begin{tabular}{|c|c|c|c|c|c|c|c|c|c|}
\hline $\begin{array}{c}\text { Mineral } \\
\text { Elements }(\mu \mathrm{g} / \mathrm{g})\end{array}$ & $\begin{array}{c}\text { Soil + 0\% } \\
\text { CFA (control) }\end{array}$ & $\begin{array}{c}\text { Soil + 0\% } \\
\text { CFA + AMF }\end{array}$ & $\begin{array}{c}\text { Soil + 0\% } \\
\text { CFA + GSH }\end{array}$ & $\begin{array}{l}\text { Soil + 7.5\% } \\
\text { CFA }\end{array}$ & $\begin{array}{l}\text { Soil + 7.5\% } \\
\text { CFA + AMF }\end{array}$ & $\begin{array}{c}\text { Soil +7.5\% } \\
\text { CFA + GSH }\end{array}$ & $\begin{array}{l}\text { Soil }+15 \% \\
\text { CFA }\end{array}$ & $\begin{array}{c}\text { Soil + 15\% } \\
\text { CFA + AMF }\end{array}$ & $\begin{array}{c}\text { Soil + 15\% } \\
\text { CFA + GSH }\end{array}$ \\
\hline $\mathrm{K}$ & $1103.35^{\mathrm{ab}}$ & $1294.25^{\mathrm{b}}$ & $966.50^{\mathrm{a}}$ & $1135.25^{\mathrm{ab}}$ & $1181.75^{\mathrm{ab}}$ & $972.85^{\mathrm{a}}$ & $1161.80^{\mathrm{ab}}$ & $1033.90^{\mathrm{a}}$ & $1028.40^{\mathrm{a}}$ \\
\hline $\mathrm{P}$ & $1327.69^{\mathrm{a}}$ & $1466.44^{\mathrm{b}}$ & $1571.39^{c}$ & $1853.34^{\mathrm{d}}$ & $2059.89^{\mathrm{e}}$ & $2081.54^{\mathrm{e}}$ & $2453.54^{f}$ & $2536.09^{f}$ & $2548.29^{f}$ \\
\hline $\mathrm{Mg}$ & $1283.69^{\mathrm{a}}$ & $1410.49^{a}$ & $1265.89^{\mathrm{a}}$ & $1946.24^{b}$ & $1977.99^{\mathrm{b}}$ & $1966.28^{b}$ & $2727.99^{c}$ & $2643.54^{c}$ & $2759.04^{c}$ \\
\hline $\mathrm{Ca}$ & $1506.42^{\mathrm{a}}$ & $1338.72^{\mathrm{a}}$ & $1322.82^{\mathrm{a}}$ & $6394.62^{\mathrm{b}}$ & $6285.67^{\mathrm{b}}$ & $6627.30^{\mathrm{b}}$ & $11331.67^{c}$ & $11381.22^{c}$ & $11846.07^{c}$ \\
\hline $\mathrm{Na}$ & $75.71^{\mathrm{a}}$ & $64.16^{\mathrm{a}}$ & $56.81^{\mathrm{a}}$ & $114.56^{\mathrm{b}}$ & $112.71^{b}$ & $131.86^{\mathrm{b}}$ & $172.21^{\mathrm{c}}$ & $156.01^{\mathrm{c}}$ & $168.56^{\mathrm{c}}$ \\
\hline $\mathrm{S}$ & $318.45^{\mathrm{a}}$ & $318.50^{\mathrm{a}}$ & $326.85^{\mathrm{a}}$ & $478.15^{\mathrm{b}}$ & $468.80^{b}$ & $507.95^{\mathrm{b}}$ & $793.90^{c}$ & $756.20^{c}$ & $810.10^{c}$ \\
\hline $\mathrm{Si}$ & $107.68^{\mathrm{ab}}$ & $124.38^{c}$ & $109.43^{\mathrm{ab}}$ & $88.18^{\mathrm{d}}$ & $65.68^{\mathrm{e}}$ & $118.13^{\text {bc }}$ & $103.98^{\mathrm{a}}$ & $69.43^{\mathrm{e}}$ & $69.38^{\mathrm{e}}$ \\
\hline B & $13.28^{\mathrm{a}}$ & $11.43^{\mathrm{a}}$ & $10.28^{\mathrm{a}}$ & $36.83^{\mathrm{b}}$ & $35.48^{\mathrm{b}}$ & $39.33^{\mathrm{b}}$ & $75.28^{\mathrm{d}}$ & $67.13^{c}$ & $72.58^{\mathrm{d}}$ \\
\hline $\mathrm{Al}$ & $12341.63^{\mathrm{ab}}$ & $13395.93^{\text {bc }}$ & $11142.88^{\mathrm{a}}$ & $13865.93^{\mathrm{bcd}}$ & $13846.73^{\mathrm{bcd}}$ & $12895.70^{\mathrm{abc}}$ & $15575.08^{d}$ & $13802.13^{\mathrm{bcd}}$ & $14804.18^{\mathrm{cd}}$ \\
\hline $\mathrm{Fe}$ & $15061.46^{\mathrm{abc}}$ & $14273.06^{\mathrm{ab}}$ & $13898.86^{\mathrm{a}}$ & $16563.81^{\text {cde }}$ & $16468.46^{\text {cde }}$ & $15564.44^{\text {bcd }}$ & $18869.11^{\mathrm{f}}$ & $16919.86^{\text {de }}$ & $17547.11^{\text {ef }}$ \\
\hline Mn & $1057.96^{\mathrm{a}}$ & $1010.76^{\mathrm{a}}$ & $991.86^{\mathrm{a}}$ & $1014.01^{\mathrm{a}}$ & $959.06^{\mathrm{a}}$ & $1011.66^{\mathrm{a}}$ & $580.98^{\mathrm{b}}$ & $501.96^{\mathrm{b}}$ & $489.61^{\mathrm{b}}$ \\
\hline Co & $9.75^{\mathrm{a}}$ & $9.75^{\mathrm{a}}$ & $9.50^{\mathrm{a}}$ & $10.55^{\mathrm{a}}$ & $10.50^{\mathrm{a}}$ & $9.48^{\mathrm{a}}$ & $10.75^{\mathrm{a}}$ & $9.90^{\mathrm{a}}$ & $10.25^{\mathrm{a}}$ \\
\hline
\end{tabular}

Data with different alphabets indicate significant differences between treatments ( $\mathrm{p}<0.05$, Duncan multiple range test). 


\subsection{Mineral Elements Uptake $(\mu \mathrm{g} / \mathrm{g})$ by Switchgrass after 90 Days Pot Study}

The concentrations of mineral elements in the roots and shoots of switchgrass after 90 days of greenhouse pot exposure to different treatments of CFA-soil admixtures are presented in Table 3 and Table 4 respectively. The concentrations of the mineral elements in the plant roots ranged from $0.75 \mu \mathrm{g} / \mathrm{g}$ for Co to $47685.64 \mu \mathrm{g} / \mathrm{g}$ for $\mathrm{K}$. The concentrations of the mineral elements in the plant shoots ranged from $0.27 \mu \mathrm{g} / \mathrm{g}$ for Co to $52590.14 \mu \mathrm{g} / \mathrm{g}$ for $\mathrm{K}$. The concentrations of $\mathrm{Mg}, \mathrm{Ca}, \mathrm{Na}, \mathrm{S}, \mathrm{B}$, and Co were higher in the CFA exposed roots while $\mathrm{P}, \mathrm{Si}, \mathrm{Al}$, and $\mathrm{Fe}$ were lower compared to the control (Table 3). Likewise, P, Mg, Ca, $\mathrm{Na}, \mathrm{S}, \mathrm{B}, \mathrm{Al}$, and $\mathrm{Co}$ were higher in the CFA-exposed shoots while $\mathrm{Fe}$ was lower compared to the control (Table 4). K and Mn were higher in plant roots and shoots exposed to $7.5 \%$ CFA-soil and lower at 15\% CFA-soil compared to the control. Si in plant shoot was lower at
7.5\% CFA and higher at 15\% CFA compared to the control.

The plant tissues mineral elements uptake in the CFA-soil admixtures were also varied with AMF inoculation or fortification with GSH. Concentrations of $\mathrm{P}, \mathrm{Mg}, \mathrm{Ca}$, and $\mathrm{S}$ were higher in plant roots exposed to AMF-inoculated CFA-soil admixtures compared to the uninoculated (Table 3) while $\mathrm{P}$ and $\mathrm{Mg}$ were also higher in plant shoots exposed to AMF (Table 4). Conversely, Si in both plant roots and shoots exposed to AMF-inoculated CFA-soil admixtures were lower than the uninoculated. S in plant roots and shoots, and $\mathrm{P}$ in plant shoots exposed to GSH fortified CFA-soil admixtures were higher compared to the admixtures without GSH. Conversely, Al, Fe, and Co in plant roots, and B in plant shoots exposed to GSH fortified CFA-soil admixtures were lower than the admixtures without GSH. All other mineral elements in the plant roots and shoots exposed to either AMF or GSH were either higher or lower at different levels of the CFA-soil admixtures.

Table 3. Average values of mineral elements uptake by switchgrass roots after $\mathbf{9 0}$ days of greenhouse pot study

\begin{tabular}{|c|c|c|c|c|c|c|c|c|c|}
\hline $\begin{array}{l}\text { Mineral } \\
\text { Elements } \\
(\mu \mathrm{g} / \mathrm{g})\end{array}$ & $\begin{array}{c}\text { Soil + } \\
0 \% \text { CFA } \\
\text { (control) }\end{array}$ & $\begin{array}{c}\text { Soil + } \\
0 \% \text { CFA } \\
+ \text { AMF }\end{array}$ & $\begin{array}{c}\text { Soil + } \\
0 \% \text { CFA } \\
+ \text { GSH }\end{array}$ & $\begin{array}{c}\text { Soil + } \\
7.5 \% \text { CFA }\end{array}$ & $\begin{array}{c}\text { Soil + } \\
\text { 7.5\% CFA } \\
+ \text { AMF }\end{array}$ & $\begin{array}{c}\text { Soil + } \\
\text { 7.5\% CFA } \\
+ \text { GSH }\end{array}$ & $\begin{array}{c}\text { Soil + } \\
\text { 15\% CFA }\end{array}$ & $\begin{array}{c}\text { Soil + } \\
\text { 15\% CFA } \\
+ \text { AMF }\end{array}$ & $\begin{array}{c}\text { Soil + } \\
\text { 15\% CFA } \\
+ \text { GSH }\end{array}$ \\
\hline K & $40437.54^{\mathrm{a}}$ & $46031.54^{\mathrm{a}}$ & $47685.64^{\mathrm{a}}$ & $41423.14^{\mathrm{a}}$ & $38923.44^{\mathrm{a}}$ & $25718.04^{b}$ & $18652.48^{b}$ & $24403.84^{b}$ & $18572.84^{b}$ \\
\hline $\mathrm{P}$ & $3340.92^{\mathrm{ab}}$ & $3790.62^{d}$ & $3266.92^{\mathrm{ac}}$ & $3198.02^{c}$ & $3498.82^{\mathrm{e}}$ & $3531.32^{\mathrm{e}}$ & $1979.44^{\mathrm{f}}$ & $3431.42^{\text {be }}$ & $2314.32^{\mathrm{g}}$ \\
\hline $\mathrm{Mg}$ & $3490.80^{\mathrm{ab}}$ & $3794.40^{\mathrm{ab}}$ & $3020.90^{\mathrm{b}}$ & $3807.10^{\mathrm{ab}}$ & $5384.30^{c}$ & $4140.60^{\mathrm{ab}}$ & $3504.60^{\mathrm{ab}}$ & $4498.40^{\mathrm{bc}}$ & $2997.50^{\mathrm{b}}$ \\
\hline $\mathrm{Ca}$ & $818.10^{\mathrm{a}}$ & $1082.90^{\mathrm{b}}$ & $797.90^{\mathrm{a}}$ & $1329.90^{\mathrm{d}}$ & $1620.00^{c}$ & $1293.60^{\mathrm{d}}$ & $1376.80^{\text {de }}$ & $1876.70^{f}$ & $1484.40^{\mathrm{e}}$ \\
\hline $\mathrm{Na}$ & $207.10^{\mathrm{a}}$ & $233.60^{\mathrm{a}}$ & $208.50^{\mathrm{a}}$ & $554.70^{\mathrm{bc}}$ & $529.40^{\mathrm{b}}$ & $574.60^{c}$ & $732.20^{\mathrm{d}}$ & $936.50^{\mathrm{e}}$ & $664.90^{f}$ \\
\hline S & $1491.60^{\mathrm{a}}$ & $1550.70^{b}$ & $1545.40^{\mathrm{b}}$ & $2273.10^{c}$ & $2735.70^{d}$ & $2511.00^{\mathrm{e}}$ & $2858.80^{f}$ & $4163.00^{\mathrm{g}}$ & $3166.00^{\mathrm{h}}$ \\
\hline Si & $799.44^{\mathrm{a}}$ & $759.14^{\mathrm{ab}}$ & $884.14^{\mathrm{c}}$ & $713.04^{\mathrm{b}}$ & $612.34^{\mathrm{e}}$ & $700.24^{\mathrm{bd}}$ & $705.68^{\text {bd }}$ & $631.64^{\text {de }}$ & $580.14^{\mathrm{e}}$ \\
\hline B & $4.78^{\mathrm{a}}$ & $4.08^{\mathrm{a}}$ & $2.88^{\mathrm{a}}$ & $34.18^{\mathrm{b}}$ & $29.68^{\mathrm{b}}$ & $28.68^{b}$ & $32.36^{\mathrm{b}}$ & $60.28^{c}$ & $48.58^{d}$ \\
\hline $\mathrm{Al}$ & $744.60^{\mathrm{a}}$ & $595.40^{\mathrm{b}}$ & $667.30^{c}$ & $361.50^{d}$ & $280.80^{\mathrm{ef}}$ & $316.60^{\text {de }}$ & $249.00^{\mathrm{fg}}$ & $301.70^{\mathrm{ef}}$ & $200.70^{\mathrm{g}}$ \\
\hline $\mathrm{Fe}$ & $641.16^{\mathrm{a}}$ & $526.46^{\mathrm{b}}$ & $565.56^{\mathrm{b}}$ & $356.66^{c}$ & $301.96^{\mathrm{c}}$ & $341.16^{c}$ & $305.72^{c}$ & $352.66^{\mathrm{c}}$ & $238.96^{d}$ \\
\hline $\mathrm{Mn}$ & $88.36^{\mathrm{a}}$ & $108.36^{\mathrm{b}}$ & $91.36^{\mathrm{a}}$ & $125.26^{\mathrm{c}}$ & $74.46^{\mathrm{d}}$ & $74.16^{\mathrm{d}}$ & $59.72^{\mathrm{e}}$ & $51.76^{\mathrm{ef}}$ & $40.76^{\mathrm{f}}$ \\
\hline Co & $1.06^{\mathrm{abc}}$ & $0.76^{\mathrm{a}}$ & $0.96^{\mathrm{ab}}$ & $1.56^{\mathrm{de}}$ & $1.26^{\mathrm{bcd}}$ & $1.16^{\mathrm{bc}}$ & $1.32^{\mathrm{cd}}$ & $1.76^{\mathrm{e}}$ & $1.06^{\mathrm{abc}}$ \\
\hline
\end{tabular}

Data with different alphabets indicate significant differences between treatments $(\mathrm{p}<0.05$, Duncan multiple range test).

Table 4. Average values of mineral elements uptake by switchgrass shoots after 90 days of greenhouse pot study

\begin{tabular}{|c|c|c|c|c|c|c|c|c|c|}
\hline $\begin{array}{l}\text { Mineral } \\
\text { Elements } \\
(\mu \mathrm{g} / \mathrm{g})\end{array}$ & $\begin{array}{c}\text { Soil + } \\
0 \% \text { CFA } \\
\text { (control) }\end{array}$ & $\begin{array}{c}\text { Soil + } \\
0 \% \text { CFA } \\
+ \text { AMF } \\
\end{array}$ & $\begin{array}{c}\text { Soil + } \\
0 \% \text { CFA } \\
+ \text { GSH } \\
\end{array}$ & $\begin{array}{c}\text { Soil + } \\
7.5 \% \text { CFA }\end{array}$ & $\begin{array}{c}\text { Soil + } \\
\text { 7.5\% CFA } \\
+ \text { AMF }\end{array}$ & $\begin{array}{c}\text { Soil + } \\
\text { 7.5\% CFA } \\
+ \text { GSH } \\
\end{array}$ & $\begin{array}{c}\text { Soil + } \\
15 \% \text { CFA }\end{array}$ & $\begin{array}{c}\text { Soil + } \\
\text { 15\% CFA } \\
+ \text { AMF } \\
\end{array}$ & $\begin{array}{c}\text { Soil + } \\
\text { 15\% CFA } \\
+ \text { GSH } \\
\end{array}$ \\
\hline K & $47605.64^{\mathrm{a}}$ & $46319.24^{b}$ & $47328.44^{\mathrm{a}}$ & $49916.54^{c}$ & $52590.14^{\mathrm{d}}$ & $52935.34^{d}$ & $23355.68^{e}$ & $49286.94^{\mathrm{C}}$ & $48993.94^{c}$ \\
\hline $\mathrm{P}$ & $3183.72^{\mathrm{a}}$ & $3804.62^{b}$ & $3733.22^{c}$ & $4993.22^{\mathrm{d}}$ & $5954.62^{\mathrm{e}}$ & $5783.72^{f}$ & $3433.44^{\mathrm{g}}$ & $6731.32^{\mathrm{h}}$ & $4680.72^{\mathrm{i}}$ \\
\hline $\mathrm{Mg}$ & $3903.40^{\mathrm{a}}$ & $3970.80^{\mathrm{a}}$ & $4287.70^{\mathrm{b}}$ & $4474.40^{\mathrm{c}}$ & $5283.50^{d}$ & $4984.30^{\mathrm{e}}$ & $4311.40^{\mathrm{b}}$ & $5156.70^{f}$ & $4301.90^{b}$ \\
\hline $\mathrm{Ca}$ & $3191.90^{\mathrm{a}}$ & $3047.10^{\mathrm{a}}$ & $4679.40^{b}$ & $3652.70^{\mathrm{a}}$ & $4583.60^{\mathrm{b}}$ & $3617.10^{\mathrm{a}}$ & $3728.40^{\mathrm{a}}$ & $3744.80^{\mathrm{a}}$ & $3385.70^{\mathrm{a}}$ \\
\hline $\mathrm{Na}$ & $109.50^{\mathrm{a}}$ & $104.00^{\mathrm{a}}$ & $109.60^{\mathrm{a}}$ & $144.30^{\mathrm{b}}$ & $135.30^{\mathrm{b}}$ & $143.90^{\mathrm{b}}$ & $260.20^{c}$ & $161.30^{\mathrm{b}}$ & $200.50^{d}$ \\
\hline $\mathrm{S}$ & $2069.80^{\mathrm{a}}$ & $2052.60^{\mathrm{b}}$ & $2194.80^{c}$ & $2840.10^{d}$ & $2476.20^{\mathrm{e}}$ & $2957.10^{f}$ & $2139.80^{g}$ & $2705.10^{\mathrm{h}}$ & $2364.10^{\mathrm{i}}$ \\
\hline $\mathrm{Si}$ & $497.84^{\mathrm{a}}$ & $367.24^{\mathrm{a}}$ & $457.64^{\mathrm{a}}$ & $456.74^{\mathrm{a}}$ & $390.74^{\mathrm{a}}$ & $456.24 a$ & $942.28^{b}$ & $385.04^{\mathrm{a}}$ & $387.64^{\mathrm{a}}$ \\
\hline B & $28.88^{\mathrm{a}}$ & $13.48^{\mathrm{b}}$ & $11.28^{\mathrm{b}}$ & $236.48^{d}$ & $143.08^{c}$ & $225.78^{d}$ & $256.76^{\mathrm{e}}$ & $304.68^{f}$ & $211.58^{\mathrm{g}}$ \\
\hline $\mathrm{Al}$ & $26.50^{\text {abc }}$ & $17.60^{\mathrm{a}}$ & $30.00^{\mathrm{abc}}$ & $27.60^{\text {abc }}$ & $40.20^{c}$ & $37.20^{\mathrm{bc}}$ & $28.20^{\text {abc }}$ & $30.70^{\text {abc }}$ & $19.60^{\mathrm{ab}}$ \\
\hline $\mathrm{Fe}$ & $168.86^{\mathrm{a}}$ & $140.16^{\mathrm{ab}}$ & $132.86^{\mathrm{b}}$ & $136.26^{\mathrm{b}}$ & $152.36^{\mathrm{ab}}$ & $137.76^{\mathrm{b}}$ & $135.52^{\mathrm{b}}$ & $122.56^{\mathrm{b}}$ & $92.16^{\mathrm{c}}$ \\
\hline Mn & $39.46^{\mathrm{a}}$ & $45.16^{\mathrm{b}}$ & $42.86^{c}$ & $42.36^{\mathrm{c}}$ & $34.86^{d}$ & $34.06^{d}$ & $28.18^{\mathrm{e}}$ & $20.26^{\mathrm{f}}$ & $18.86^{\mathrm{f}}$ \\
\hline Co & $0.27^{\mathrm{a}}$ & $0.27^{\mathrm{a}}$ & $0.27^{\mathrm{a}}$ & $0.36^{\mathrm{a}}$ & $0.36^{\mathrm{a}}$ & $0.36^{\mathrm{a}}$ & $0.68^{\mathrm{b}}$ & $0.36^{\mathrm{a}}$ & $0.36^{\mathrm{a}}$ \\
\hline
\end{tabular}

Data with different alphabets indicate significant differences between treatments ( $<<0.05$, Duncan multiple range test). 
The bioaccumulation (BAF), enrichment (EF), and translocation (TF) factors for each mineral element taken up by the plant tissues are presented in Table 5, Table 6 and Table 7 respectively. BAF was greater than 1 unit for $\mathrm{K}, \mathrm{P}$ (except in 7.5\% CFA-soil admixture inoculated with AMF and in 15\% CFA-soil admixtures), Mg, $\mathrm{Na}, \mathrm{S}$, and $\mathrm{Si}$ in all CFA-soil admixtures with or without AMF or
GSH (Table 5). Similarly, EF was greater than 1 unit for $\mathrm{K}, \mathrm{P}, \mathrm{Mg}, \mathrm{Ca}$ (except in control soil), $\mathrm{Na}, \mathrm{S}, \mathrm{Si}$, and $\mathrm{B}$ (Table 6). TF was greater than 1 unit for $\mathrm{K}$ (except in 0\% CFA-soil containing GSH), P (except in control soil), $\mathrm{Mg}, \mathrm{Ca}, \mathrm{S}$ (except in 7.5\% CFA-soil containing AMF and 15\% CFA-soil), B, and Si (except in 15\% CFA) (Table 7).

Table 5. Bioaccumulation factor (BAF) of mineral elements by switchgrass roots after 90 days of greenhouse pot study

\begin{tabular}{|c|c|c|c|c|c|c|c|c|c|}
\hline $\begin{array}{l}\text { Mineral } \\
\text { Elements } \\
(\mu \mathrm{g} / \mathrm{g})\end{array}$ & $\begin{array}{c}\text { Soil + } \\
0 \% \text { CFA } \\
\text { (control) }\end{array}$ & $\begin{array}{c}\text { Soil + } \\
0 \% \text { CFA } \\
+ \text { AMF }\end{array}$ & $\begin{array}{c}\text { Soil + } \\
0 \% \text { CFA } \\
+ \text { GSH }\end{array}$ & $\begin{array}{c}\text { Soil + } \\
\text { 7.5\% CFA }\end{array}$ & $\begin{array}{c}\text { Soil + } \\
\text { 7.5\% CFA } \\
+ \text { AMF }\end{array}$ & $\begin{array}{c}\text { Soil + } \\
\text { 7.5\% CFA } \\
+ \text { GSH }\end{array}$ & $\begin{array}{c}\text { Soil + } \\
\text { 15\% CFA }\end{array}$ & $\begin{array}{c}\text { Soil + } \\
15 \% \text { CFA } \\
+ \text { AMF }\end{array}$ & $\begin{array}{c}\text { Soil + } \\
\text { 15\% CFA } \\
+ \text { GSH }\end{array}$ \\
\hline $\mathrm{K}$ & 36.65 & 35.57 & 49.34 & 36.49 & 32.94 & 26.44 & 16.05 & 23.60 & 18.06 \\
\hline $\mathrm{P}$ & 2.52 & 2.58 & 2.08 & 1.73 & 1.70 & 1.70 & 0.81 & 1.35 & 0.91 \\
\hline $\mathrm{Mg}$ & 2.72 & 2.69 & 2.39 & 1.96 & 2.72 & 2.11 & 1.28 & 1.70 & 1.09 \\
\hline $\mathrm{Ca}$ & 0.54 & 0.81 & 0.60 & 0.21 & 0.26 & 0.20 & 0.12 & 0.16 & 0.13 \\
\hline $\mathrm{Na}$ & 2.74 & 3.64 & 3.67 & 4.84 & 4.70 & 4.36 & 4.25 & 6.00 & 3.94 \\
\hline $\mathrm{S}$ & 4.68 & 4.87 & 4.73 & 4.75 & 5.84 & 4.94 & 3.60 & 5.51 & 3.91 \\
\hline $\mathrm{Si}$ & 7.42 & 6.10 & 8.08 & 8.09 & 9.32 & 5.93 & 6.79 & 9.10 & 8.36 \\
\hline B & 0.36 & 0.36 & 0.28 & 0.93 & 0.84 & 0.73 & 0.43 & 0.90 & 0.67 \\
\hline $\mathrm{Al}$ & 0.06 & 0.04 & 0.06 & 0.03 & 0.02 & 0.02 & 0.02 & 0.02 & 0.01 \\
\hline $\mathrm{Fe}$ & 0.04 & 0.04 & 0.04 & 0.02 & 0.02 & 0.02 & 0.02 & 0.02 & 0.01 \\
\hline $\mathrm{Mn}$ & 0.08 & 0.11 & 0.09 & 0.12 & 0.08 & 0.07 & 0.10 & 0.10 & 0.08 \\
\hline Co & 0.11 & 0.08 & 0.10 & 0.15 & 0.12 & 0.12 & 0.12 & 0.18 & 0.10 \\
\hline
\end{tabular}

Table 6. Enrichment factor (EF) of mineral elements by switchgrass shoots after 90 days of greenhouse pot study

\begin{tabular}{|c|c|c|c|c|c|c|c|c|c|}
\hline $\begin{array}{l}\text { Mineral } \\
\text { Elements } \\
(\mu \mathrm{g} / \mathrm{g})\end{array}$ & $\begin{array}{c}\text { Soil + } \\
0 \% \text { CFA } \\
\text { (control) }\end{array}$ & $\begin{array}{c}\text { Soil + } \\
0 \% \text { CFA } \\
+ \text { AMF }\end{array}$ & $\begin{array}{c}\text { Soil + } \\
0 \% \text { CFA } \\
+ \text { GSH }\end{array}$ & $\begin{array}{c}\text { Soil + } \\
\text { 7.5\% CFA }\end{array}$ & $\begin{array}{c}\text { Soil + } \\
\text { 7.5\% CFA } \\
+ \text { AMF } \\
\end{array}$ & $\begin{array}{c}\text { Soil + } \\
\text { 7.5\% CFA } \\
+ \text { GSH } \\
\end{array}$ & $\begin{array}{c}\text { Soil + } \\
\text { 15\% CFA }\end{array}$ & $\begin{array}{c}\text { Soil + } \\
\text { 15\% CFA } \\
+ \text { AMF }\end{array}$ & $\begin{array}{c}\text { Soil + } \\
\text { 15\% CFA } \\
+ \text { GSH }\end{array}$ \\
\hline K & 43.15 & 35.79 & 48.97 & 43.97 & 44.50 & 54.41 & 20.10 & 47.67 & 47.64 \\
\hline $\mathrm{P}$ & 2.40 & 2.59 & 2.38 & 2.69 & 2.89 & 2.78 & 1.40 & 2.65 & 1.84 \\
\hline $\mathrm{Mg}$ & 3.04 & 2.82 & 3.39 & 2.30 & 2.67 & 2.53 & 1.58 & 1.95 & 1.56 \\
\hline $\mathrm{Ca}$ & 2.12 & 2.28 & 3.54 & 0.57 & 0.73 & 0.55 & 0.33 & 0.33 & 0.29 \\
\hline $\mathrm{Na}$ & 1.45 & 1.62 & 1.93 & 1.26 & 1.20 & 1.09 & 1.51 & 1.03 & 1.19 \\
\hline $\mathrm{S}$ & 6.50 & 6.44 & 6.72 & 5.94 & 5.28 & 5.82 & 2.70 & 3.58 & 2.92 \\
\hline $\mathrm{Si}$ & 4.62 & 2.95 & 4.18 & 5.18 & 5.95 & 3.86 & 9.06 & 5.55 & 5.59 \\
\hline B & 2.17 & 1.18 & 1.10 & 6.42 & 4.03 & 5.74 & 3.41 & 4.54 & 2.92 \\
\hline $\mathrm{Al}$ & 0.002 & 0.001 & 0.003 & 0.002 & 0.003 & 0.003 & 0.002 & 0.002 & 0.001 \\
\hline $\mathrm{Fe}$ & 0.01 & 0.01 & 0.01 & 0.01 & 0.01 & 0.01 & 0.01 & 0.01 & 0.01 \\
\hline Mn & 0.04 & 0.04 & 0.04 & 0.04 & 0.04 & 0.03 & 0.05 & 0.04 & 0.04 \\
\hline Co & 0.03 & 0.03 & 0.03 & 0.03 & 0.03 & 0.04 & 0.06 & 0.04 & 0.04 \\
\hline
\end{tabular}

Table 7. Translocation factor (TF) of mineral elements by switchgrass shoots after 90 days of greenhouse pot study

\begin{tabular}{|c|c|c|c|c|c|c|c|c|c|}
\hline $\begin{array}{c}\text { Mineral } \\
\text { Elements } \\
(\mu \mathrm{g} / \mathrm{g})\end{array}$ & $\begin{array}{c}\text { Soil + } \\
0 \% \text { CFA } \\
\text { (control) }\end{array}$ & $\begin{array}{c}\text { Soil + } \\
0 \% \text { CFA } \\
+ \text { AMF }\end{array}$ & $\begin{array}{c}\text { Soil + } \\
0 \% \text { CFA } \\
+ \text { GSH }\end{array}$ & $\begin{array}{c}\text { Soil + } \\
\text { 7.5\% CFA }\end{array}$ & $\begin{array}{c}\text { Soil + } \\
\text { 7.5\% CFA } \\
+ \text { AMF }\end{array}$ & $\begin{array}{c}\text { Soil + } \\
\text { 7.5\% CFA } \\
+ \text { GSH }\end{array}$ & $\begin{array}{c}\text { Soil + } \\
15 \% \text { CFA }\end{array}$ & $\begin{array}{c}\text { Soil + } \\
15 \% \text { CFA } \\
+ \text { AMF }\end{array}$ & $\begin{array}{c}\text { Soil + } \\
\text { 15\% CFA } \\
+ \text { GSH }\end{array}$ \\
\hline $\mathrm{K}$ & 1.18 & 1.01 & 0.99 & 1.21 & 1.35 & 2.06 & 1.25 & 2.02 & 2.64 \\
\hline $\mathrm{P}$ & 0.95 & 1.00 & 1.14 & 1.56 & 1.70 & 1.64 & 1.73 & 1.96 & 2.02 \\
\hline $\mathrm{Mg}$ & 1.12 & 1.05 & 1.42 & 1.18 & 0.98 & 1.20 & 1.23 & 1.15 & 1.44 \\
\hline $\mathrm{Ca}$ & 3.90 & 2.81 & 5.86 & 2.75 & 2.83 & 2.80 & 2.71 & 2.00 & 2.28 \\
\hline $\mathrm{Na}$ & 0.53 & 0.45 & 0.53 & 0.26 & 0.26 & 0.25 & 0.36 & 0.17 & 0.30 \\
\hline S & 1.39 & 1.32 & 1.42 & 1.25 & 0.91 & 1.18 & 0.75 & 0.65 & 0.75 \\
\hline $\mathrm{Si}$ & 0.62 & 0.48 & 0.52 & 0.64 & 0.64 & 0.65 & 1.34 & 0.61 & 0.67 \\
\hline B & 6.04 & 3.30 & 3.92 & 6.92 & 4.82 & 7.87 & 7.93 & 5.05 & 4.36 \\
\hline $\mathrm{Al}$ & 0.04 & 0.03 & 0.04 & 0.08 & 0.14 & 0.12 & 0.11 & 0.10 & 0.10 \\
\hline $\mathrm{Fe}$ & 0.26 & 0.27 & 0.23 & 0.38 & 0.50 & 0.40 & 0.44 & 0.35 & 0.39 \\
\hline $\mathrm{Mn}$ & 0.45 & 0.42 & 0.47 & 0.34 & 0.47 & 0.46 & 0.47 & 0.39 & 0.46 \\
\hline Co & 0.25 & 0.36 & 0.28 & 0.23 & 0.29 & 0.31 & 0.52 & 0.20 & 0.34 \\
\hline
\end{tabular}


Table 8. Switchgrass glucose and bioethanol yield (mean \pm SD) in the CFA-soil admixtures

\begin{tabular}{|c|c|c|c|}
\hline Treatments & Glucose ( $\mu \mathrm{g} / \mathrm{mg} \mathrm{DW})$ & Bioethanol ( $\mu \mathrm{g} / \mathrm{mg} \mathrm{DW})$ & Bioethanol Yield (\%) \\
\hline Soil + 0\% CFA (control) & $281.13 \pm 17.67^{\mathrm{a}}$ & $24.46 \pm 2.79^{\mathrm{ab}}$ & 17.00 \\
\hline Soil + 0\% CFA + AMF & $401.76 \pm 14.59^{\mathrm{b}}$ & $30.07 \pm 5.33^{\text {abcd }}$ & 14.54 \\
\hline Soil + 0\% CFA + GSH & $392.92 \pm 29.06^{\mathrm{b}}$ & $35.98 \pm 5.56^{\mathrm{d}}$ & 17.89 \\
\hline Soil + 7.5\% CFA & $311.23 \pm 11.12^{\mathrm{c}}$ & $23.27 \pm 8.40^{\mathrm{a}}$ & 14.62 \\
\hline Soil + 7.5\% CFA + AMF & $217.59 \pm 12.92^{\mathrm{d}}$ & $32 . .83 \pm 5.29^{\mathrm{bcd}}$ & 29.50 \\
\hline Soil + 15\% CFA & $345.90 \pm 19.12^{\mathrm{e}}$ & $26.63 \pm 6.01^{\mathrm{abc}}$ & 15.06 \\
\hline Soil + 15\% CFA + AMF & $309.19 \pm 13.29^{c}$ & $30.05 \pm 2.97^{\text {abcd }}$ & 18.99 \\
\hline Soil + 15\% CFA + GSH & $228.79 \pm 12.13^{\mathrm{d}}$ & $26.87 \pm 6.67^{\mathrm{abc}}$ & 22.97 \\
\hline
\end{tabular}

Data with different alphabets indicate significant differences between treatments ( $<<0.05$, Duncan multiple range test).

The concentrations of glucose from the enzymatic hydrolysis of MAA pretreated biomass, and bioethanol concentrations in the fermented hydrolysate are presented in Table 8. Glucose concentration ranged from 217.59 $401.76 \mu \mathrm{g} / \mathrm{mg}$ DW. Glucose concentrations in biomass hydrolysate increased significantly $(p<0.05)$ in $7.5 \%$ and $15 \%$ CFA-soil admixtures compared to the control. The presence of AMF inoculum in the admixtures enhanced glucose production from switchgrass biomass grown on control soil and 15\% CFA soil-admixture. Likewise, GSH enhanced glucose production from biomass grown on control soil (Table 8). Bioethanol concentration ranged from 23.27 - $35.98 \mu \mathrm{g} / \mathrm{mg}$ DW. Bioethanol concentration was highest in fermented hydrolysate obtained from switchgrass grown on 15\% CFA-amended soil. AMF and GSH enhanced bioethanol concentration in CFA-amended soils and the unamended soil (Table 8). However, relative to the glucose concentration in the hydrolysate, bioethanol yield ranged from $14.54-29.50 \%$. Bioethanol yield was lower in the CFA-amended soils compared to the control soil. Meanwhile, the bioethanol yield was enhanced in the fermented hydrolysate of switchgrass grown on CFA-amended soils that were inoculated with AMF or fortified with GSH.

\section{Discussion}

The presence of essential plant nutrient elements including $\mathrm{K}, \mathrm{Ca}, \mathrm{Mg}, \mathrm{S}, \mathrm{P}, \mathrm{Fe}, \mathrm{Mn}, \mathrm{B}$, and Co in CFA [31,32,33,34] made CFA a suitable source of nutrient supply to soils where there is nutrient deficiency. The CFA used in this study had higher levels of $\mathrm{K}, \mathrm{Mg}, \mathrm{Ca}, \mathrm{Na}$, $\mathrm{S}, \mathrm{B}, \mathrm{Al}$, and Fe, and lower levels of $\mathrm{P}, \mathrm{Si}, \mathrm{Mn}$, and Co compared to the ASL soil. The differences in the levels of these mineral elements between the CFA and ASL soil were significant for $\mathrm{Mg}, \mathrm{Ca}, \mathrm{Na}, \mathrm{S}, \mathrm{Si}, \mathrm{B}, \mathrm{Al}, \mathrm{Mn}$, and Co. The application of CFA to ASL soil at rates 7.5 and 15\% increased the levels $\mathrm{P}, \mathrm{Mg}, \mathrm{Ca}, \mathrm{Na}, \mathrm{S}, \mathrm{B}$, and $\mathrm{Co}$, and decreased the levels of $\mathrm{K}, \mathrm{Al}, \mathrm{Fe}$, and $\mathrm{Mn}$ in the resulting CFA-soil admixtures (Table 1). Roy and Joy [35] in their study on the dose-related effect of CFA on edaphic properties in laterite cropland soil reported that $\mathrm{Ca}$ and $\mathrm{Na}$ increased with CFA dose and time, but K decreased. Dash et al. [36] also reported decreased levels of $\mathrm{P}$ and $\mathrm{K}$, and increased level of Fe with increased CFA amendment rate.
After 90 days of cultivating switchgrass on the CFA-soil admixtures, the levels of $\mathrm{K}, \mathrm{P}, \mathrm{Mg}, \mathrm{Ca}, \mathrm{Na}, \mathrm{S}, \mathrm{B}$, $\mathrm{Al}, \mathrm{Fe}$, and Co were still higher in the soils amended with CFA compared to the unamended (Table 2). AMF inoculation increased the levels of $\mathrm{K}, \mathrm{P}, \mathrm{Mg}, \mathrm{Si}$, and $\mathrm{Al}$ in the control soil increased $\mathrm{K}, \mathrm{P}$, and $\mathrm{Mg}$ in the $7.5 \%$ CFA-soil admixture, and increased $\mathrm{P}$ and $\mathrm{Ca}$ in the $15 \%$ CFA-soil admixture compared to the uninoculated admixtures (Table 2). Likewise, GSH fortification increased the levels of $\mathrm{P}, \mathrm{S}$, and $\mathrm{Si}$ in the control soil, increased $\mathrm{P}, \mathrm{Mg}, \mathrm{Ca}, \mathrm{Na}$, $\mathrm{S}, \mathrm{Si}$, and $\mathrm{B}$ in the $7.5 \%$ CFA-soil admixture and increased $\mathrm{P}, \mathrm{Mg}, \mathrm{Ca}$, and $\mathrm{S}$ in the 15\% CFA-soil admixture compared to unfortified admixtures (Table 2). Significant positive and negative interrelationships between the mineral elements in the CFA-soil admixtures varied with the rates of CFA-amendment and with time.

CFA increased the uptake of $\mathrm{Mg}, \mathrm{Ca}, \mathrm{Na}, \mathrm{S}, \mathrm{B}$, and $\mathrm{Co}$ in the plant roots and decreased $\mathrm{P}, \mathrm{Si}, \mathrm{Al}$, and $\mathrm{Fe}$ (Table 3 ). Likewise, CFA increased the uptake of $\mathrm{P}, \mathrm{Mg}, \mathrm{Ca}, \mathrm{Na}, \mathrm{S}$, $\mathrm{B}, \mathrm{Al}$, and $\mathrm{Co}$ in the plant shoots and decreased the $\mathrm{Fe}$ uptake. The uptake of $\mathrm{K}$ and $\mathrm{Mn}$ in the plant roots and shoots were increased and decreased at 7.5 and 15\% CFA-soil admixtures respectively, while the uptake of $\mathrm{Si}$ in the plant shoot decreased and increased at 7.5 and $15 \%$ CFA rates respectively. Nass et al. [37] reported higher uptake of $\mathrm{Al}, \mathrm{B}, \mathrm{Co}$, and $\mathrm{Fe}$ in grasses grown on unweathered CFA-contaminated soils. Swamy et al. [38] also reported increased uptake of K, P, Fe, Mn, and Co in Onion bulbs (Allium cepa L) grown on CFA-amended soils at rates beyond 5\% CFA.

AMF have been reported to assist various plants in assimilating mineral elements especially phosphorus (P) $[39,40,41,42,43]$. In this study, AMF enhanced the uptake of P, Mg, Ca, and S in the plant roots (Table 3), enhanced the uptake of $\mathrm{P}$ and $\mathrm{Mg}$ in the plant shoots (Table 4), and reduced the uptake of $\mathrm{Si}$ in both the plant roots and shoots. Similarly, GSH enhanced the uptake of S in plant roots and shoots, and $\mathrm{P}$ in plant shoots while it reduced the uptake of $\mathrm{Al}, \mathrm{Fe}$, and $\mathrm{Co}$ in plant roots, and $\mathrm{B}$ in plant shoots. The AMF or GSH either enhanced or decreased the uptake of all other mineral elements in the plant roots and shoots at different exposure levels to CFA in the admixtures.

$\mathrm{BAF}$ is the ratio of mineral element concentration in plant roots to soil $[44,45]$. EF is the ratio of mineral element concentration in plant shoot to soil $[45,46,47]$. TF 
is the ratio of mineral element in plant shoots to roots $[45,48,49,50]$. BAF, EF, and TF have been used in environmental toxicology and risk assessment as essential indices to assess plant tolerance and to determine plants efficiency for potential mineral element uptake [45,51]. The switchgrass BAF was highest for K (16.05 - 49.34) and least for $\mathrm{Fe}$ and $\mathrm{Al}(<0.06)$ (Table 5), the $\mathrm{EF}$ was highest for $\mathrm{K}(20.10-54.41)$ and least for $\mathrm{Al}(<0.01)$ (Table 6), and the TF was highest for B (3.30 - 7.93) and least for $\mathrm{Al}(<0.15)$ (Table 7). The BAF, EF, and TF were varied with CFA amendment rates, AMF inoculation and GSH fortification. The high-efficiency translocation of a potentially toxic trace element such as B may pose a threat to the growth of plants $[52,53]$ when exposed CFA $[54,55,56]$.

Various studies have been conducted to determine reducing sugar (glucose) and ethanol yield from lignocellulosic biomass [30,57,58,59]. Typically, most of the lignocellulosic biomass from agriculture consists of about 40\%-50\% cellulose, 20\%-30\% hemicellulose, and $10 \%-25 \%$ lignin [60]. Cellulose is an unbranched linear polymer of $\beta$-( $1 \rightarrow 4)$-D-glucopyranose units. Hemicellulose is a branched linear polymer derived from anhydrides of various sugars with low degree of polymerization, low mechanical and chemical resistance, and always accompanied by cellulose and lignin. Lignin is a complex cross-linked, 3-dimensional non-carbohydrate polymer formed from phenolic units. Lignin provides strength and structure to the plant cell walls and it acts as a barrier for solutions or enzymes by linking to both hemicelluloses and cellulose [60]. To optimize glucose yield from switchgrass, shoot biomass were subjected to microwave-assisted nitric acid pretreatment [57] followed by enzymatic hydrolysis with Accelerase 1500 (Endoglucanase Activity: 2200 - 2800 CMC U/g; Beta-Glucosidase Activity: 450 - 775 pNPG U/g).

Glucose concentration in hydrolysate varied between CFA amendments, AMF inoculation, and GSH fortification (Table 8). Glucose concentration in biomass hydrolysate of switchgrass grown on CFA-amended soils was significantly increased compared to the unamended soil. The differences in the glucose concentration may be due to the relative differences in their elemental uptake. The concentrations of certain mineral elements in biomass may enhance or inhibit the activities of the accelerase (or cellulase) enzyme $[61,62,63,64,65]$. Both AMF and GSH enhanced glucose yield in unamended soils. Tutt et al. [57] achieved the highest cellulose-to-glucose conversion rate of $316.7 \mathrm{~g} / \mathrm{kg}$ from wheat straw biomass pretreated with nitric acid. Xie et al. [6] also reported an increase in sugar yield from sugarcane grown in metal-contaminated soils.

Bioethanol concentration in fermented hydrolysate varied between CFA amendments, AMF inoculation, and GSH fortification (Table 8). The concentration of bioethanol was higher in the fermented hydrolysate of switchgrass grown in 15\% CFA-amended soil compared to the unamended soil. However, the bioethanol yield relative to the glucose concentration was lower in the CFA-amended soils compared to the control, AMF enhanced the bioethanol yield from switchgrass biomass grown on the CFA-amended soils. Likewise, GSH enhanced bioethanol yield from switchgrass biomass grown on the CFA-amended and unamended soils. Studies conducted by Xie et al. [6] and Balsamo et al. [65] have also shown no significant adverse effect on bioethanol production from biomass grown on contaminated soils.

\section{Conclusion}

CFA contains mineral elements that could supplement soils that are lacking in specific nutrients for bioenergy crop production. However, the amount of CFA needed in amending the soil is crucial to the downstream production of glucose and bioethanol. The co-application of CFA with either AMF or GSH as soil amendment would serve to better enhance bioethanol production from biomass that may be impacted by the CFA.

\section{Acknowledgements}

This research was financially supported in part by Golden Key International Honours Society Research Grant (Awarded to Olushola M. Awoyemi). The grant body had no role in the study design, data collection and analysis, decision to publish, or preparation of the manuscript.

\section{References}

[1] D.C. Adriano, A.L. Page, A.A. Elseewi, A.C. Chang, I.A. Satraughan, Utilisation and disposal of fly ash and other coal residues in terrestrial ecosystems: a review, J. Environ. Qual. 9 (1980) 333-345

[2] O. Babajide, L. Petrik, N. Musyoka, B. Amigun, F. Ameer, Use of coal fly ash as a catalyst in the production of biodiesel, Petrol Coal 52 (4) (2010) 261-272.

[3] E.K. Dzantor, Potentials for beneficial utilization of coal fly ash for biofuel feedstock production on marginal/degraded lands, in: R.K. Behl, R.N. Chibbar, S. Jain, V.P. Bahl, N.E. Bassam (Eds.), Renewable Energy, Sources and Applications, Agrobios (International) Publishers, Jodhpur, India, 2013, p. 346-360.

[4] Q. Wang, Y. Dong, Y. Cui, X. Liu, Instances of soil and crop heavy metal contamination in China, Soil Sediment Contam. 10 (5) (2001) 497-510.

[5] C. Lin, W. Lu, Y. Wu, Agricultural soils irrigated with acidic mine water: Acidity, heavy metals, and crop contamination, Aust. J. Soil Res. 43 (7) (2005) 819-826.

[6] J. Xie, Q. Weng, G. Ye, S. Luo, R. Zhu, A. Zhang, X. Chen, C. Lin, Bioethanol Production from Sugarcane Grown in Heavy Metal-Contaminated Soils, BioResour. 9 (2) (2014) 2509-2520.

[7] L. Jamai, K. Ettayebi, Y. J. El-Yamani, M. Ettayebi, Production of ethanol from starch by free and immobilized Candida tropicalis in the presence of $\alpha$-amylase, Bioresour. Technol. 98 (14) (2007) 2765-2770.

[8] F.W. Bai, W.A. Anderson, M. Moo-Young, Ethanol fermentation technologies from sugar and starch feedstocks, Biotechnol. Adv. 26 (1) (2008) 89-105.

[9] A. Demirbas, Biofuels sources, biofuel policy, biofuel economy and global biofuel projections, Energy Convers. Manage. 49 (8) (2008) 2106-2116.

[10] S. Amin, Review on biofuel oil and gas production processes from microalgae, Energy Convers. Manage. 50 (7) (2009) 1834-1840.

[11] C.N. Ibeto, A.U. Ofoefule, K.E.A. Agbo, Global overview of biomass potentials for bioethanol production: A renewable alternative fuel, Trends Appl. Sci. Res. 6 (5) (2011) 410-425.

[12] J. Goldemberg, Ethanol for a sustainable energy future, Science 315 (5813) (2007) 808-810.

[13] O.J. Sánchez, C.A. Cardona, Trends in biotechnological production of fuel ethanol from different feedstocks, Bioresour. Technol. 99 (13) (2008) 5270-5295. 
[14] S.T. Anderson, The demand for ethanol as a gasoline substitute, J. Environ. Econ. Manage. 63 (2) (2008) 151-168.

[15] P.F.A. Shikida, A. Finco, B.F. Cardoso, A Comparison Between Ethanol and Biodiesel Production: The Brazilian and European Experiences, in: V.A. Galante, D. Rahmeier, D. Bentivoglio, M.A. Rasetti, D. Padula, (Eds.), Liquid Biofuels: Emergence, Development and Prospects, Lecture Notes in Energy 27, Springer-Verlag London, p. 25-53.

[16] Foreign Agricultural Service (FAS), U.S. Ethanol Exports Rebound in 2014. International Agricultural Trade Report, United States Department of Agriculture, April 28, 2015 https://www.fas.usda.gov/sites/default/files/2015-04/042015_ethanol_iatr.pdf. Accessed $2^{\text {nd }}$ March, 2017.

[17] M.R. Schmer, K.P. Vogel, R.B. Mitchell, R.K Perrin, Net energy of cellulosic ethanol from switchgrass, PNAS, 105 (2) (2008) 464-469.

[18] P.R. Adler, M.A. Sanderson, A.A. Boateng, P.J. Weimer, H.G. Jung, Biomass Yield and Biofuel Quality of Switchgrass Harvested in Fall or Spring, J. Agron. 98 (2006) 1518-1525.

[19] G.E. Varvel, K.P. Vogela, R.B. Mitchell, R.F. Follett, J.M. Kimble, Comparison of corn and switchgrass on marginal soils for bioenergy, Biomass Bioenerg. 32 (2008) 18-21.

[20] M.K. Kering, J.T. Biermacher, T.J. Butler, J. Mosali, J.A. Guretzky, Biomass Yield and Nutrient Responses of Switchgrass to Phosphorus Application, Bioenerg. Res. 5 (2012) 71-78.

[21] C. Brown, J. Skousen, T. Griggs, Yield of switchgrass on reclaimed surface mines, JASMR. 2 (1) (2013) 38-48.

[22] P. Perego, S.B. Howell, Molecular mechanisms controlling sensitivity to toxic metal ions in yeast, Toxicol. Appl. Pharmacol. 147 (2) (1997) 312-318.

[23] D. Pearce, F. Sherman, Toxicity of copper, cobalt, and nickel salts is dependent on histidine metabolism in the yeast Saccharomyces cerevisiae, J. Bacteriol. 181 (1999) 4774-4779.

[24] M. Azenha, M.T. Vasconcelos, P. Moradas-Ferreira, The influence of $\mathrm{Cu}$ concentration on ethanolic fermentation by Saccharomyces cerevisiae, J. Biosci. Bioeng. 90 (2) (2000) 163-167.

[25] P.J. Weimer, B.S. Dien, T.L. Springer, K.P. Vogel, In vitro gas production as a surrogate measure of the fermentability of cellulosic biomass to ethanol, Appl. Microbiol. Biotechnol. 67 (2005) 52-58.

[26] B.S. Dien, H.G. Jung, K.P. Vogel, M.D. Casler, J.F.S. Lamb, P.J. Weimer, L. Iten, R.B. Mitchell, G. Sarath, Chemical composition and response to dilute-acid pretreatment and enzymatic saccharification of alfalfa, reed canarygrass, and switchgrass, Biomass Bioenerg. 30 (2006) 880-891.

[27] United States Environmental Protection Agency, Microwave assisted acid digestion of sediments, sludges, soils, and oils, USEPA method 3051A, 2007.

http://www.epa.gov/osw/hazard/testmethods/sw846/pdfs/3051a.pd f. Accessed $14^{\text {th }}$ March, 2015

[28] United States Environmental Protection Agency, Microwave Assisted Digestion of Siliceous and Organically Based Matrices, USEPA method 3052, $3^{\text {rd }}$ ed., U.S. EPA, Office of Solid Waste and Emergency Response, Washington, D.C. 1996. http://www.epa.gov/epaoswer/hazwaste/test/pdfs/3052.pdf. Accessed 15 December 2014.

[29] C. Shih, Determination of saccharides and ethanol from biomass conversion using Raman spectroscopy: effects of pretreatment and enzyme composition, Graduate Theses and Dissertation, 2010, Paper 11596

[30] M. Brodeur-Campbell, J. Klinger, D. Shonnard, Feedstock mixture effects on sugar monomer recovery following dilute acid pretreatment and enzymatic hydrolysis, Bioresour. Technol. 116 (2012) (2012) 320-326

[31] I.A.M. Yunusa, P. Loganathan, S.P. Nissanka, V. Manoharan, M.D. Burchett, C.G. Skilbeck, D. Eamus, Application of Coal Fly Ash in Agriculture: A Strategic Perspective, Crit. Rev. Environ. Sci. Technol. 42 (6) (2012) 559-600.

[32] C.R. Lal, S.K. Jha, R.C. Tripathi, R.E. Masto, V.A. Selvi, Remediation of fly ash landfills through plantation, in: Remediation Autumn, Wiley Periodicals, Inc. 2008, p. 71-90.

[33] M. Basu, M. Pande, P.B.S. Bhadoria, S.C. Mahapatra, Potential fly-ash utilisation in agriculture: A global review, Prog. Nat. Sci. 19 (2009) 1173-1186.

[34] C.D. Tsadilas, Agricultural use of fly ash: Expected benefits and consequences. WACAU-2014, Israel International Workshop on Agricultural Coal Ash Uses, $27-29^{\text {th }}$ May 2014. http://coal-
ash.co.il/sadna14/Tsadilas_FlyAshUse.pdf. Accessed $3^{\text {rd }}$ March 2015.

[35] G. Roy, V.C. Joy, Dose-related effect of fly ash on edaphic properties in laterite cropland soil, Ecotoxicol. Environ. Saf. 74 (2011) 769-775.

[36] A. Dash, A. Pradhan, S. Das, S. Mohanty, Fly ash as a potential source of soil amendment in agriculture and a component of integrated plant nutrient supply system, J. Ind. Pollut. Contr. 31(2) (2015) 249-257.

[37] M.M. Nass, T.M. Lexmond, M.L. van Beusichem, M. Janssen-Jurkovíc, Long-term supply and uptake by plants of elements from coal fly ash, Commun. Soil Sci. Plant Anal. 24 (9-10) (2008) 899-913.

[38] T. Swamy, N. Dash, G. Nahak, B. Deo, R. Sahu, Effect of Coal Fly Ash on Growth, Biochemistry, Cytology and Heavy Metal Content of Allium cepa L, NY Sci. J. 3 (5) (2010) 10-16.

[39] J.J. Brejda, D.H. Yocom, L.E. Moser, S.S. Waller, Dependence of 3 Nebraska Sandhills Warm-Season Grasses on VesicularArbuscular Mycorrhizae, J. Range Manage. 46 (1) (1993) 14-20.

[40] R.B. Clark, Differences among mycorrhizal fungi for mineral uptake per root length of switchgrass grown in acidic soil, J. Plant Nutr. 25 (8) (2002) 1753-1772.

[41] D.J. Parrish, J.H. Fike, The Biology and Agronomy of Switchgrass for Biofuels, Crit. Rev. Plant Sci. 24 (5-6) (2005) 423-459.

[42] A. Balliu, G. Sallaku, B. Rewald, AMF Inoculation Enhances Growth and Improves the Nutrient Uptake Rates of Transplanted, Salt-Stressed Tomato Seedlings, Sustainability 7 (12) (2015) 15967-15981.

[43] A. Hashem, E.F. Abdul-Allah, A.A. Alqarawi, A.A. Al-Huqail, S. Wirth, D. Egamberdieva, The Interaction between Arbuscular Mycorrhizal Fungi and Endophytic Bacteria Enhances Plant Growth of Acacia gerrardii under Salt Stress, Front. Microbiol. 7 (2016) 1089, p. 15.

[44] N. Badr, M. Fawzy, K.M. Al-Qahtani, Phytoremediation: An Ecological Solution to Heavy-Metal-Polluted Soil and Evaluation of Plant Removal Ability, World Appl. Sci. J. 16 (9) (2012) 1292-1301.

[45] S.N. Majid, A.I. Khwakaram, G.A. Mam-Rasul, Z.H. Ahmed, Bioaccumulation, Enrichment and Translocation Factors of some Heavy Metals in Typha Angustifolia and Phragmites Australis Species Growing along Qalyasan Stream in Sulaimani City /IKR, J. Zankoy Sulaimani 16A (4) (2014) 93-109.

[46] R.A. Sutherland, C.A. Tolosa, F.M.G. Tack, M.G. Verloo, Characterization of selected element concentration and enrichment ratios in background and anthropogenically impacted roadside areas, Arch. Environ. Contam. Toxicol. 38 (2000) 428-438.

[47] K.B. Mmolawa, A.S. Likuku, G.K. Gaboutloeloe, Assessment of heavy metal pollution in soils along major roadside areas in Botswana, Afric. J. Environ. Sci. Technol. 5 (2011) 186-196.

[48] M. Srivastava, L.Q. Ma, J.A.G. Santos, Three new arsenic hyperaccumulating ferns, Sci. Total Environ. 364 (2006) 24-31.

[49] J. Yoon, X. Cao, Q. Zhou, L.Q. Ma, Accumulation of Pb, $\mathrm{Cu}$, and $\mathrm{Zn}$ in native plants growing on a contaminated Florida site. Sci. Total Environ. 368 (2006) 456-464.

[50] A.R. Usman, H.M. Mohamed, Effect of microbial inoculation and EDTA on the uptake and translocation of heavy metal by corn and sunflower, Chemosphere 76 (2009) 893-899.

[51] M. Ghosh, S.P. Singh, A comparative study of cadmium phytoextraction by accumulator and weed species, Environ. Pollut. 133 (2005) 365-371.

[52] L.M. Cervilla, B. Blasco, J.J. Rios, L. Romero, J.M. Ruiz, Oxidative Stress and Antioxidants in Tomato (Solanum lycopersicum) Plants Subjected to Boron Toxicity, Ann. Bot. 100 (2007) 747-756.

[53] M. Ayvaz, M.K. Avci, C. Yamaner, M. Koyuncu, A. Guven, K. Fagerstedt, Does excess boron affect the malondialdehyde levels of potato cultivars? Eurasia. J. Biosci. 7 (2013) 47-53.

[54] R.O. Nable, G.S. Bañuelos, J.G. Paull, Boron toxicity, Plant Soil 193 (1997) 181-198.

[55] P.B. Woodbury, G. Rubin, D.C. McCune, L.H. Weinstein, E.F. Neuhauser, Assessing Trace Element Uptake by Vegetation on a Coal Fly Ash Landfill, Water Air Soil Pollut. 111 (1) (1999) 271-286.

[56] P.E. Rothrock, G.C. Manning, Report: Potential Impact of Fly-ash Groundwater Contamination on Vegetation of Cowles Bog, Indiana Dunes National Lakeshore, Randall Environmental Center Taylor University Upland, IN 46989-1001 August 2011. https://www3.epa.gov/region5/cleanup/rcra/nipsco/pdfs/nipscoareac-report-201108.pdf. Accessed $25^{\text {th }}$ February, 2017. 
[57] M. Tutt, T. Kikas, J. Olt, Influence of different pretreatment methods on bioethanol production from wheat straw, Agron. Res. Biosyst. Eng. Special Issue 1 (2010) 269-276.

[58] I.Y. Sunwoo, C.H. Ra, G.T. Jeong, S.K. Kim, Evaluation of ethanol production and bioadsorption of heavy metals by various red seaweeds, Bioproc. Biosyst. Eng. 39 (6) (2016) 915-923.

[59] T. Vintila, A. Negrea, H. Barbu, R. Sumalana, K. Kovacsd, Metal distribution in the process of lignocellulosic ethanol production from heavy metal contaminated sorghum biomass, J. Chem. Technol. Biotechnol. 91 (2016) 1607-1614.

[60] P. Puligundla, S. Oh, C. Mok, Microwave-assisted pretreatment technologies for the conversion of lignocellulosic biomass to sugars and ethanol: a review, Carbon Lett. 17 (1) (2016) 1-10.

[61] N.J. Cao, Q. Xu, C.S. Chen, C.S. Gong, F. Chen, Cellulose hydrolysis usingv zinc chloride as a solvent and catalyst, Appl. Biochem. Biotechnol. 45 (1) (1994) 521-530.
[62] G. Geiger, H. Brandi, G. Furner, R. Schulin, The effect of copper on the activity of cellulose and $\beta$-glucosidase in the presence of montmorillonite or Al-montmorillonite, Soil Biol. Biochem. 30 (1998) $1537-1544$.

[63] A. Karaca, S.C. Cetin, O.C. Turgay, R. Kizilkaya, Effects of Heavy Metals on Soil Enzyme Activities, in: I. Sherameti, A. Varma (Eds.), Soil Heavy Metals, Springer-Verlag Berlin Heidelberg, Soil Biol. 19 (2010) 237-262.

[64] S. Shakoor, S. Aftab, A. Rehman, Characterization of Cellulose Degrading Bacterium, Bacillus megaterium S3, Isolated from Indigenous Environment, Pak. J. Zool. 45 (6) (2013) 1655-1662.

[65] R.A. Balsamo, W.J. Kelly, J.A. Satrio, M.N. Ruiz-Felix, M. Fetterman, R. Wynn, K. Hagel, Utilization of Grasses for Potential Biofuel Production and Phytoremediation of Heavy Metal Contaminated Soils, Int. J. Phytoremediat. 17 (5) (2015) 448-455. 